\title{
UNA ESPECIE NUEVA DE FUIRENA (CYPERACEAE) DEL ESTADO DE CAMPECHE (MÉXICO)
}

\author{
Clara Hilda Ramos Álvarez \\ Av. del Imán 580 \\ Edif. Helios, Depto. 101 \\ 04700 México, D.F. \\ Y \\ Nelly Diego-Pérez \\ Facultad de Ciencias \\ Universidad Nacional Autónoma de México \\ Ciudad Universitaria, Circuito Exterior \\ 04510 México, D.F.
}

\section{RESUMEN}

Se describe Fuirena stephani sp. nov., con material proveniente del estado de Campeche, México. F. stephani se distingue de F. robusta Kunth principalmente por la forma del verticilo externo de la flor. Hasta ahora sólo se conoce de una localidad.

Palabras clave: Fuirena, Cyperaceae, Campeche.

\section{ABSTRACT}

Fuirena stephani sp. nov., is described from plants collected in the state of Campeche, Mexico. $F$. stephani can be distinguished from $F$. robusta Kunth, by the shape of the outer perianth set. It is known at present only from one locality.

Key words: Fuirena, Cyperaceae, Campeche.

\section{INTRODUCCIÓN}

Entre las colectas realizadas en la región de Calakmul, Campeche, financiadas principalmente por la Comisión Nacional para el Estudio de la Biodiversidad y el Instituto de Biología de la Universidad Nacional Autónoma de México, se encontró una especie del género Fuirena que debido a sus características se propone como nueva. 
Fuirena stephani Ramos et N. Diego, sp. nov. Fig. 1.

Fuirena stephani sp. nov., Fuirenae robustae Kunth similis, sed differt ligula ciliata, perianthii partibus verticilli externi fusiformibus, inaequalibus, una in regione centrali latiore, ungue geniculato.

Hierbas perennes, cespitosas. Tallos de 0.60 a $1.50 \mathrm{~m}$ de alto, los entrenudos se alargan hacia la parte media y se acortan hacia la región distal, los basales miden de 5 a $8 \mathrm{~cm}$ de largo, los medios alcanzan de 10 a $20 \mathrm{~cm}$ y los distales de 5 a $12 \mathrm{~cm}$. Hojas ensiformes, 5 nervadas; en los ejemplares observados hasta de $30 \mathrm{~cm}$ largo y $3.5 \mathrm{~cm}$ de ancho en la zona más amplia; las basales son las más cortas y las apicales las más angostas; sobre la nervadura del haz en especial hacia la base, presentan algunos cilios y pelos cortos; las jóvenes poseen cilios en el envés sobre las nervaduras prominentes. Vainas foliares de 4 a $6 \mathrm{~cm}$ de largo, cilíndricas, algo plegadas en la región basal, lisas en la distal, con el orificio asimétrico, glabras; a veces las inferiores sin lámina. Lígulas ciliadas, de 1 a $2 \mathrm{~mm}$ de alto en forma de anillo asimétrico, siguiendo el borde del orificio, escariosas. Inflorescencias 1 a 3 por nudo, distribuidas en la región distal del tallo, cimosas, con pedúnculos de ca. $3 \mathrm{~cm}$ de largo, ascendentes; cada cima está compuesta de 3-7 glomérulos de espiguillas; glomérulos ovoides, de 5-8(9) $\mathrm{mm}$ de largo, el central sésil, los laterales con pedúnculos de 9 a $10 \mathrm{~mm}$ de largo, pubescentes. Cada glomérulo presenta en su base una bráctea mucronada, el cuerpo de la bráctea mide de 2.5 a $2.7 \mathrm{~mm}$ de largo y $2.5 \mathrm{~mm}$ de ancho, ovada, auriculada, pubescente en la superficie abaxial, sobre todo hacia la región distal donde también es ciliada, el mucrón de 0.4 a $0.5 \mathrm{~mm}$ de largo, pubescente, se observa como la prolongación de 3 nervaduras centrales prominentes que convergen distalmente. Glumas ovadas, aristadas, de $2 \mathrm{~mm}$ de largo y $1.7 \mathrm{~mm}$ de ancho; la arista de $1.5 \mathrm{~mm}$ de largo, pubescente, se separa de la lámina abaxialmente un poco antes del ápice, lámina cortamente pubescente en la superficie abaxial por encima de su base, ciliadas. Flores bisexuales, perianto compuesto de 2 verticilos, el externo con 3 segmentos desiguales entre sí, de 0.7 a $1.4 \mathrm{~mm}$ de largo, lineares, fusiformes, uno de ellos notablemente más ancho en la región central, con la uña geniculada y un mucrón de 0.4 a $0.6 \mathrm{~mm}$ de largo en la región distal; el verticilo interno presenta 3 láminas de $2.2 \mathrm{~mm}$ de largo y $1.2 \mathrm{~mm}$ de ancho, ovadas, con una nervadura central, unguiculadas, apiculadas, amarillentas, engrosadas, estrigulosas, las uñas rectas; estambres 3, filamentos aplanados, de 1 a $1.5 \mathrm{~mm}$ de largo, anteras lineares, mucronadas, de 1.5 a $1.7 \mathrm{~mm}$ de largo y 0.1 a $0.3 \mathrm{~mm}$ de ancho. Aquenios obovoides, de $2.1 \mathrm{~mm}$ de largo, rostrados, trígonos, ángulos agudos, lados convexos o aplanados, estipitados, glabros.

TIPO: México, Campeche, Calakmul, a 200 m al E de Rancho Las Delicias, camino Xpujil-La Moza, altitud 225 m s.n.m., 18²9'25" N, 89'15'56" W, 30 de abril 2001, E. Martínez S. y C. H. Ramos 33815 (Holotipo MEXU; isotipos BIGUA, BM, EAP, ENCB, FCME, $\mathrm{K}, \mathrm{MO}, \mathrm{UACAM}, \mathrm{XAL})$.

Paratipo: Misma localidad, 27 de abril 1998, E. Martínez S., D. Álvarez y C. Galindo 30716 (IEB, MEXU).

Fenología: florece y fructifica de marzo a mayo. 
Ramos y Diego-Pérez: Una Especie Nueva de Fuirena del estado de Campeche
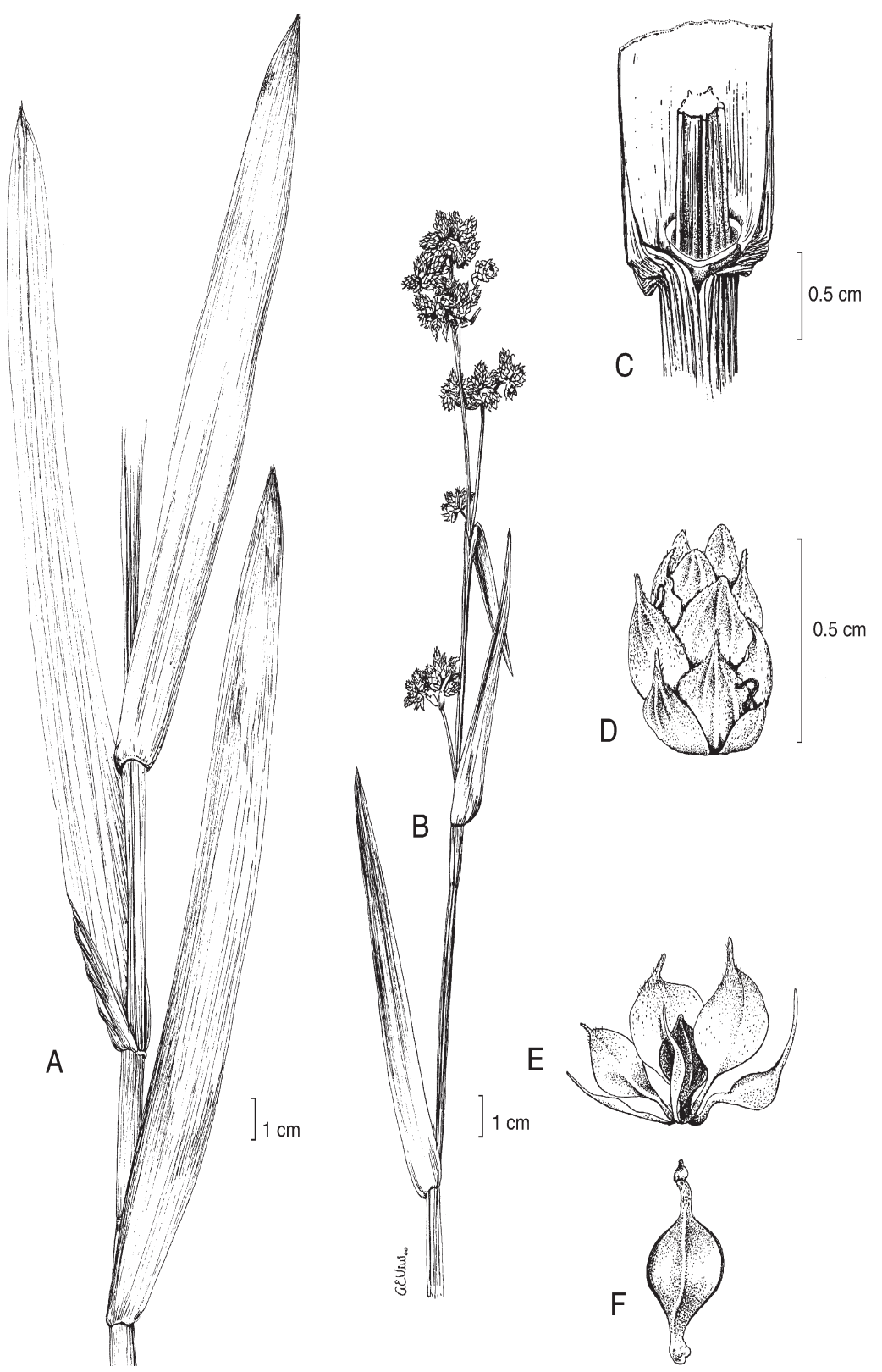

Fig. 1. Fuirena stephani Ramos et N. Diego. A. Tallo y hojas; B. Inflorescencia; C. Lígula; D. Espiguilla; E. Flor; F. Aquenio. (E. Martínez S. et al. 30716, MEXU). Ilustrado por Ana Elena Viniegra. 
Hábitat: El lugar donde se colectó esta especie es un humedal sometido a disturbio. Se localiza en medio de un potrero, a pleno sol y muy cerca de la carretera. A la fecha sólo se conoce de la localidad tipo por las dos colectas referidas. Es posible que exista en condiciones semejantes en los estados de Tabasco y Quintana Roo. El trabajo de campo realizado nos permite establecer que es una planta escasa en la región.

A continuación se presenta una clave para distinguirla de otras especies de Fuirena conocidas de México.

1 Perianto compuesto exclusivamente de cerdas, a veces ausente

F. incompleta

1 Perianto laminar o mixto, compuesto de tubérculos, cerdas y láminas.

2 Perianto exclusivamente laminar.

3 Láminas del perianto infladas distalmente, con un mucrón de ca. $0.5 \mathrm{~mm}$ de largo, setuloso, a veces ausente. F. camptotricha

3 Láminas del perianto con el ápice emarginado o truncado, con un mucrón duro de ca. $1 \mathrm{~mm}$ largo, escabriúsculo F. umbellata

2 Perianto mixto de cerdas o tubérculos y láminas anchas o fusiformes.

4 Elementos externos del perianto reducidos a tubérculos apiculados, los internos laminares inflados distalmente con una arista apical ........................ F. repens

4 Elementos externos del perianto cerdosos o fusiformes, los internos laminares con el ápice agudo, redondeado o emarginado.

5 Elementos externos del perianto cerdosos.

6 Cerdas lisas; láminas con el ápice agudo o acuminado F. robusta

6 Cerdas retrobarbadas; láminas con el ápice emarginado o redondeado y un mucrón apical retrobarbado F. simplex

5 Elementos externos del perianto fusiformes, desiguales entre sí, los internos laminares, ovados, apiculados F. stephani

Fuirena stephani se asemeja superficialmente en estado vegetativo a $F$. robusta, especie con amplia distribución en el sur de México, pero difiere de ella por presentar la vaina siempre glabra, aunque en $F$. robusta a veces es glabra, la lígula ciliada, la inflorescencia menos expandida, de apariencia más rígida y el verticilo externo del perianto con sus elementos fusiformes.

Etimología: Esta especie es nombrada en honor de Esteban Martínez, distinguido botánico mexicano, quien durante muchos años se ha dedicado a la recolecta de plantas en diferentes estados del país, contribuyendo así al conocimiento de la flora nacional y al incremento del acervo de los herbarios nacionales. Sus colectas sirvieron de base para este trabajo.

\section{AGRADECIMIENTOS}

Agradecemos profundamente al Doctor Fernando Chiang Cabrera por la revisión crítica del manuscrito y la elaboración de la diagnosis latina; a la Bióloga Ana Elena Viniegra por la ilustración, al Biól. Ramiro Cruz por el apoyo técnico y a Andrea Castro 
Ramos y Diego-Pérez: Una Especie Nueva de Fuirena del estado de Campeche

Jaramillo del Instituto de Biología, Universidad Nacional Autónoma de México, por su colaboración en el etiquetado del material.

\section{LITERATURA CITADA}

Adams, C. D. 1994. Fuirena Rottb., In: Davidse, G., M. Sousa \& A. Chater (eds.). Flora Mesoamericana 6. Universidad Nacional Autónoma de México (Instituto de Biología), Missouri Botanical Garden \& The Natural History Museum (London). pp: 450-452.

Kral, R. 1978. A synopsis of Fuirena (Cyperaceae) for the Americas North of South America. Sida 7(4): 309-354. 